\title{
IMPACT OF THE SIZE OF THE SENSOR PART ON SENSOR-ACTUATOR EFFICIENCY
}

\author{
Roman Trojanowski, Jerzy Wiciak \\ AGH University of Science and Technology, Cracow, Poland \\ e-mail: roman.cz.trojanowski@agh.edu.pl; jerzy.wiciak@agh.edu.pl
}

\begin{abstract}
This paper presents numerical analyses of the impact of the size of the sensor-actuator part on sensor-actuator efficiency. For that purpose, numerical models of a steel plate clamped on all sides were created with two piezoelectric actuators attached to it. One was used to excite the plate and the second (which could be either a standard actuator or a sensor-actuator, having different shapes and sensor part size) to reduce plates vibrations. Harmonic analyses were performed with the goal function being the minimum of the displacement vector sum of $n$ nodes, where $n$ can have different values depending on the case study.
\end{abstract}

Keywords: AVC, FEM, ANSYS

\section{Introduction}

The concept of active vibration reduction was introduced at the end of XIX century. Sometime later - around the 1930s, concepts for active noise reduction were formulated. One of the first works dealing with the problem of reduction of structural sounds transmitted to acoustic surrounding was that by Fuller and Jones (1987). Authors used a single electrodynamic actuator and were able to reduce acoustics pressure levels emitted by an external monopole source inside a cylindrical shell by about 10-20 dB. Still the field of active vibration control (Fuller et al., 1996; Hansen and Snyder, 1997) is constantly moving forward. Developments in material engineering, increase in technological potential, computing power allowed carrying advanced computer simulations (Augustyn and Kozień, 2015) as well as to control processes leading to vibration and noise reduction. Also an analytical approach is a subject of continuous development. New theories and mathematical models are widely used for problems of objects vibrations (Żołopa and Brański, 2014) and sound radiation (Szemela et al., 2018). Other works deal with the control type and algorithms (Gardonio and Elliott, 2005; Gardonio, 2006), combining active and passive methods (Kundu and Berry, 2011). New materials are being developed, including functionally graded materials (FGM). FGM represents a new class of composites that consist of two (or more) different materials resulting in corresponding changes in properties of the material. A basic mechanical model to determine the electric field in bimorph actuators and functionally graded actuators is presented in the papers (Tylikowski, 2001, 2004; Pietrzakowski, 2007). Loy et al. (1999) using simply supported cylindrical elements as an example proved that obtained natural frequencies depend on the volume of constituent materials and their configuration.

In their previous works, the authors concentrated on piezo actuators with a step change in materials properties. The idea behind them was that perhaps they could serve as simpler replacements for functionally graded actuators. The idea was first introduced with fairly simple models (Trojanowski and Wiciak, 2012). After some refining improved models and some analytical analyses were presented (Wiciak and Trojanowski, 2014). Another improvement was introducing the acoustic surrounding of the analysed plate (Wiciak and Trojanowski, 2015a). These works generally concluded that the introduced change in material properties of piezo actuators did 
not produce any substantial change in the levels of reduction of plates vibration. Another work presented the attempts to verify numerical results with physical experiment (Wiciak and Trojanowski, 2015b). Unfortunately, a small number of samples (they had to be custom made) and differences between said samples made the results unsatisfactory.

But from this, another idea was born. If changes to the inner part of a piezo element have a negligible influence on its effectiveness in obtained reduction levels, perhaps it could be used as a sensor. This article focuses on one side on the feasibility of the idea to introduce a sensor-actuator, and on the effect a change in the sensor size have on its effectiveness. To test this, numerical models using the FEM method were made.

\section{Numerical models}

To test the impact of the size of the sensor part of sensor-actuator, numerical models were created using ANSYS software. These models consisted of a steel plate clamped on all sides with 2 piezoelectric elements attached (Fig. 1).

(a)

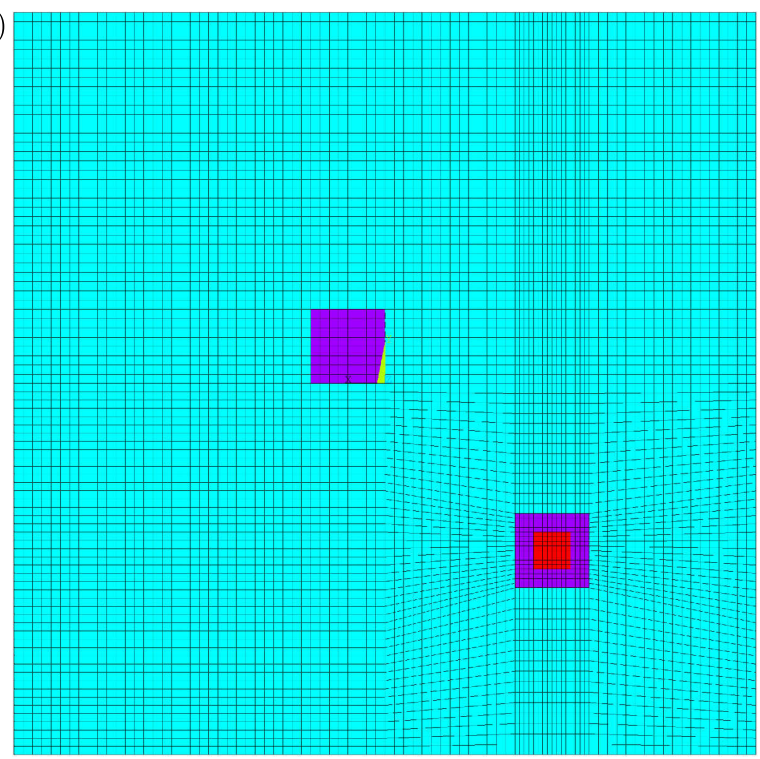

(b)

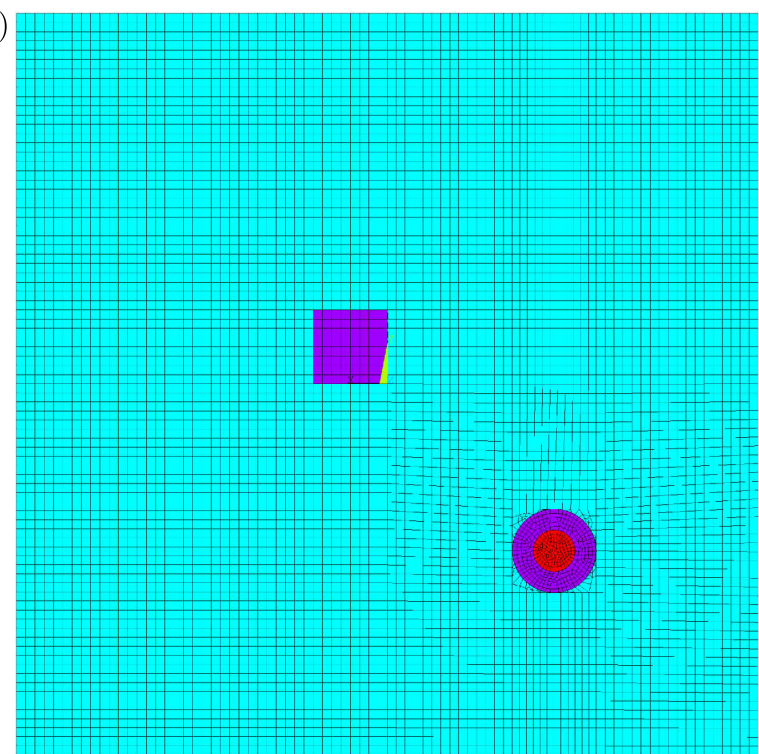

Fig. 1. Modelled plates with piezoelectric actuators

One of the elements is always a square based homogeneous element placed near the centre of the plate and is used to excite the plate. The second one can be either a square based of a disc based element used for vibration reduction. For each shape of the second piezoelectric element, there are also 2 possible variants. One is a standard homogeneous piezoelectric actuator, the other is a sensor-actuator (Fig. 2). In this second variant, the inner part of the actuator has been "turned" off.

The area size of the whole actuator (regardless of its dimensions) is $400 \mathrm{~mm}^{2}$. The height is always $1 \mathrm{~mm}$. For the sensor-actuator, there are 2 possible sizes of the inactive part of the actuator. It can be either $1 / 4$ of $1 / 16$ of the size of the whole element.

Parameters used for the models can be found in Table 1.

To determine the impact of the size of the sensor part in the sensor-actuator, a series of harmonic analyses of the 1st, 2nd, 4th and 5th mode of the plate was performed. For each of them, a voltage of $100 \mathrm{~V}$ was applied to the actuator placed near the centre of the plate to excite plates vibrations. Then an optimization procedure was performed using internal ANSYS functions to find the amplitude of the voltage that should be applied to the second actuator to 
(a)

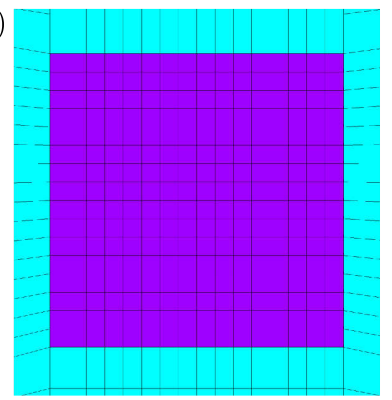

(d)

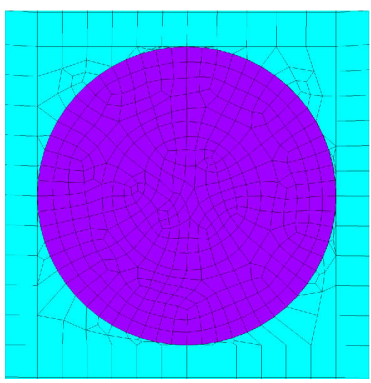

(b)

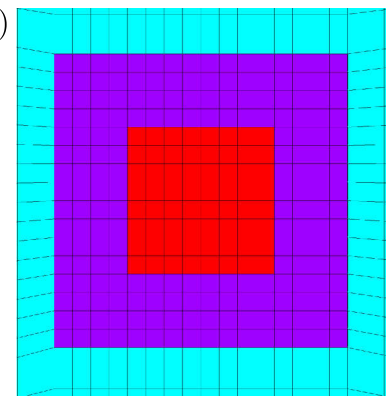

(e)

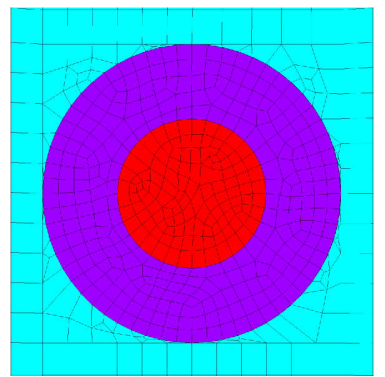

(c)

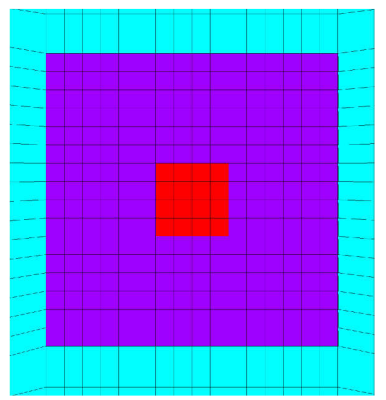

(f)

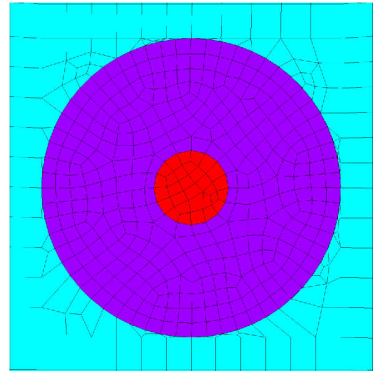

Fig. 2. Modelled actuators (a) standard square based actuator, (b) square based sensor-actuator with a larger sensor part, (c) square based sensor-actuator with a smaller sensor part, (d) standard disc based actuator, (e) disc based sensor-actuator with a larger sensor part, (f) disc based sensor-actuator with a smaller sensor part

Table 1. Models parameters

\begin{tabular}{|c|c|c|}
\hline $\begin{array}{c}\text { Structural } \\
\text { element }\end{array}$ & $\begin{array}{c}\text { Element used for } \\
\text { modeling }\end{array}$ & Properties \\
\hline \hline Plate & SOLSH190 & $\begin{array}{c}E=1.93 \cdot 10^{11} \mathrm{~Pa} \\
\nu=0.29 \\
\rho=7800 \mathrm{~kg} / \mathrm{m}^{3}\end{array}$ \\
\hline Piezo elements & SOLID226 & Properties of PZ 28 \\
\hline Air & FLUID30 & $\begin{array}{c}\rho=1.2 \mathrm{~kg} / \mathrm{m}^{3} \\
\mathrm{c}=343 \mathrm{~m} / \mathrm{s}\end{array}$ \\
\hline
\end{tabular}

reduce these vibrations. One run of the optimization procedure consisted of maximum 30 steps (if the algorithm found the optimal value the run could be ended earlier). After the completion of the first run, the optimal value obtained from it was used as a starting value in the next run, but with the range of voltage narrowed (in the first run it was 0-500 V). This was repeated several times with the final run having the voltage range $\pm 2.5 \mathrm{~V}$ of the staring value.

Since it was determined in previous works that the optimal phase angle of the voltage applied to the actuator is either $0^{\circ}$ or $180^{\circ}$ (depending on the mode), the phase angle was not a variable in the optimization procedure.

Finally, the obtained voltages were applied to the actuator responsible for reduction of plates vibration, and the obtained vibration reduction levels were noted in the results. In the event that a vibration reduction level obtained from these voltages significantly differed from other results, some amount of manual tuning (changing the starting range of the voltage) was done to the optimization procedure to double check the said result.

The goal function used in the optimization procedure is given as

$$
J_{1}=\min \sum_{i=1}^{n}\left|\mathbf{X}_{\text {sum }}(i)\right|
$$


where min is the smallest value of the sum, $\mathbf{X}_{\text {sum }}(i)$ is the displacement vector sum of the $i$-th node, $n$ is the number of nodes used for calculations.

Since there are 3 possible placements and size of the sensor used, $\mathrm{n}$ can have different values:

a) $n$ is equal to every node making the back of the plate (here the back of the plate is the side to which the piezoelectric elements are not attached) that amounts to more than 7200 nodes (the actual number changes depending on the shape of the actuators and size of the sensor part of the actuator) and is considered the best case scenario;

b) $n$ is equal to 81 nodes forming a "virtual" sensor of the size of the disc based actuator placed on the same diagonal as piezo actuators but in the upper level side of the plate (near $1 / 4$-th of its length);

c) $n$ ranges from 65 to 402 nodes forming a "virtual" sensor of the size of the "turned off" part of the sensor-actuator placed directly under the centre of the disc based actuator (the number changes depending on the size of the inner part and the shape of actuator).

\section{Results and analyses}

The reduction of vibrations was calculated as

$$
L_{\text {red }}=20 \log \frac{\sum_{i=1}^{n}\left|\mathbf{X}_{1 \text { sum }}(i)\right|}{\sum_{i=1}^{n}\left|\mathbf{X}_{2 \text { sum }}(i)\right|}
$$

where $\mathbf{X}_{1 \text { sum }}(i)$ is the displacement vector sum in the $i$-th node before the reduction, $\mathbf{X}_{2 \text { sum }}(i)$ is the displacement vector in the $i$-th node after the reduction, $n$ is the number of nodes used (as per 3 cases mentioned before).

Table 2. Results obtained for square based actuators when using the whole back area of the plate as the sensor; mode - number of mode; type - full actuator, actuator-sensor; $U_{a}$ - amplitude of the voltage applied to the actuator; $\varphi_{a}$ - phase of the voltage applied to the actuator; $L_{r e d}-$ vibration reduction

\begin{tabular}{|c|c|c|c|c|}
\hline Mode & Type & $\begin{array}{l}U_{a} \\
{[\mathrm{~V}]}\end{array}$ & $\begin{array}{l}\varphi_{a} \\
{\left[^{\circ}\right]}\end{array}$ & $\begin{array}{l}L_{\text {red }} \\
{[\mathrm{dB}]}\end{array}$ \\
\hline 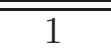 & \multirow{4}{*}{ actuator } & 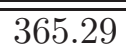 & 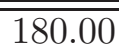 & 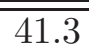 \\
\hline 2 & & 57.77 & 360.00 & 43.1 \\
\hline 4 & & 12.05 & 180.00 & 25.8 \\
\hline 5 & & 159.95 & 360.00 & 35.0 \\
\hline 1 & \multirow{4}{*}{$\begin{array}{l}\text { actuator-sensor } \\
\text { (larger) }\end{array}$} & 487.43 & 180.00 & 41.3 \\
\hline 2 & & 77.27 & 360.00 & 43.1 \\
\hline 4 & & 16.24 & 180.00 & 26.0 \\
\hline 5 & & 215.37 & 360.00 & 35.0 \\
\hline 1 & \multirow{4}{*}{$\begin{array}{l}\text { actuator-sensor } \\
\text { (smaller) }\end{array}$} & 387.09 & 180.00 & 41.3 \\
\hline 2 & & 61.24 & 360.00 & 43.1 \\
\hline 4 & & 12.87 & 180.00 & 26.0 \\
\hline 5 & & 169.86 & 360.00 & 35.0 \\
\hline
\end{tabular}

Table 2 presents the results of vibration reduction for square based actuators when using the whole back area of the plate is used as a sensor. As this is the best case scenario for the global approach to vibration reduction it will be treated as a base. In other tables (Table 3 and 4 ) there will be an additional column that will present results of vibration reduction recalculated using the whole back area for comparison to this base. Similarly, for the disc based actuators, Table 5 
presents the results when using the whole back of the plate, and Tables 6 and 7 will have this additional column.

When comparing square based sensor-actuators to the standard actuator in the base scenario (Table 2) it can be seen that the results show no significant difference in obtained vibration reduction levels (no more than $0.2 \mathrm{~dB}$ ). There is also no difference in vibration reduction levels when reducing the sensor part size of the sensor-actuator.

The difference can be seen in the voltages needed to obtain the said reduction levels. When using a sensor-actuator with the sensor area size being $1 / 4$ of the whole area of the piezoelectric element, a much higher voltage is needed to obtain similar reduction levels. After reducing the sensor part area size to 1/16 of the whole element area, the voltages required for the reduction were significantly reduced. They are still slightly higher than those needed when using the standard actuator, but are significantly closer to them.

Table 3 presents results of vibration reduction levels using square based actuators when introducing a virtual sensor placed on the same diagonal as actuators, but in the upper right quarter of the plate. As mentioned before, there is an additional column which allows for comparison between the results obtained using different sensor placements.

Similarly to the previous table, there are no significant differences in the levels of vibration reduction obtained (with the largest being $0.6 \mathrm{~dB}$ ). Similarly, after turning off the part of the actuator, the voltages needed to obtain those results are significantly higher when using a larger sensor part, and after reducing the size of that part those voltages are also reduced.

Table 3. Results obtained for square based actuators when using a "virtual" sensor on the diagonal in the upper side of the plate; mode - number of mode; type - full actuator, actuator-sensor; $U_{a}$ - amplitude of the voltage applied to the actuator; $\varphi_{a}$ - phase of the voltage applied to the actuator; $L_{r e d}$ - vibration reduction; $L_{\text {redf }}$ - vibration reduction calculated for all nodes making the back of the plate

\begin{tabular}{|c|c|c|c|c|c|}
\hline Mode & Type & $\begin{array}{l}U_{a} \\
{[\mathrm{~V}]}\end{array}$ & $\begin{array}{l}\varphi_{a} \\
{\left[^{\circ}\right]}\end{array}$ & $\begin{array}{l}L_{\text {red }} \\
{[\mathrm{dB}]}\end{array}$ & $\begin{array}{l}L_{\text {redf }} \\
{[\mathrm{dB}]}\end{array}$ \\
\hline 1 & \multirow{4}{*}{ actuator } & 365.42 & 180.00 & 44.6 & 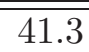 \\
\hline 2 & & 57.80 & 360.00 & 53.6 & 43.0 \\
\hline 4 & & 12.20 & 180.00 & 23.9 & 25.9 \\
\hline 5 & & 158.66 & 360.00 & 31.6 & 33.7 \\
\hline 1 & \multirow{4}{*}{$\begin{array}{l}\text { actuator-sensor } \\
\text { (larger) }\end{array}$} & 487.79 & 180.00 & 44.6 & 41.4 \\
\hline 2 & & 77.29 & 360.00 & 53.8 & 43.1 \\
\hline 4 & & 16.31 & 180.00 & 23.9 & 26.0 \\
\hline 5 & & 213.26 & 360.00 & 31.6 & 33.7 \\
\hline 1 & \multirow{4}{*}{$\begin{array}{c}\text { actuator-sensor } \\
\text { (smaller) }\end{array}$} & 387.16 & 180.00 & 44.6 & 41.3 \\
\hline 2 & & 61.24 & 360.00 & 54.0 & 43.1 \\
\hline 4 & & 12.94 & 180.00 & 23.9 & 25.9 \\
\hline 5 & & 168.43 & 360.00 & 31.6 & 33.8 \\
\hline
\end{tabular}

Table 4 presents results of vibration reduction for square based actuators when using a virtual sensor placed under the centre of the actuator (or sensor-actuator) used for reduction. It can be seen that in this case that the sensor-actuator has a larger sensor part (up to $1.1 \mathrm{~dB}$ more than for the standard actuator). This is actually a somewhat "false" reading. When comparing the results recalculated using all the nodes of the back area of the plate $\left(L_{\text {redf }}\right)$, it can be seen that again there is almost no difference between the standard actuator and the sensor-actuator with a larger sensor part. The reason for this difference is the placement of the "virtual" sensor. As it is placed under the actuator and has the size of the sensor part of the sensor actuator (for the standard actuator the size is the same as for the larger sensor part) the standard actuator has 
slightly higher reading of the displacement vector sum after the reduction (because there is a working part of the actuator on the sensor). For the sensor-actuator those readings are slightly smaller, hence the difference. But why this is not visible for the sensor-actuator with a smaller sensor part? As mentioned before, the size of the "virtual" sensor used is the same as the sensor part of the sensor-actuator. So, after reducing the sensor part, the results are more similar.

Table 4. Results obtained for square based actuators when using a "virtual" sensor placed under the centre of the square based actuator; mode - number of mode; type - full actuator, actuator-sensor; $U_{a}$ - amplitude of the voltage applied to the actuator; $\varphi_{a}$ - phase of the voltage applied to the actuator; $L_{\text {red }}$ - vibration reduction; $L_{\text {redf }}$ - vibration reduction calculated for all nodes making the back of the plate

\begin{tabular}{|c|c|c|c|c|c|}
\hline Mode & Type & $\begin{array}{l}U_{a} \\
{[\mathrm{~V}]} \\
\end{array}$ & $\begin{array}{l}\varphi_{a} \\
{\left[{ }^{\circ}\right]}\end{array}$ & $\begin{array}{l}L_{\text {red }} \\
{[\mathrm{dB}]}\end{array}$ & $\begin{array}{l}L_{\text {redf }} \\
{[\mathrm{dB}]}\end{array}$ \\
\hline 1 & \multirow{4}{*}{ actuator } & 363.40 & 180.00 & 25.4 & 39.2 \\
\hline 2 & & 57.76 & 360.00 & 41.9 & 43.1 \\
\hline 4 & & 12.27 & 180.00 & 31.4 & 25.7 \\
\hline 5 & & 161.03 & 360.00 & 33.4 & 34.4 \\
\hline 1 & \multirow{4}{*}{$\begin{array}{l}\text { actuator-sensor } \\
\text { (larger) }\end{array}$} & 485.30 & 180.00 & 25.9 & 39.2 \\
\hline 2 & & 77.30 & 360.00 & 42.6 & 43.1 \\
\hline 4 & & 16.38 & 180.00 & 32.1 & 25.9 \\
\hline 5 & & 216.19 & 360.00 & 34.5 & 34.6 \\
\hline 1 & \multirow{4}{*}{$\begin{array}{l}\text { actuator-sensor } \\
\text { (smaller) }\end{array}$} & 384.90 & 180.00 & 25.4 & 38.9 \\
\hline 2 & & 61.29 & 360.00 & 41.7 & 42.9 \\
\hline 4 & & 12.93 & 180.00 & 31.8 & 25.9 \\
\hline 5 & & 170.81 & 360.00 & 33.2 & 34.4 \\
\hline
\end{tabular}

Table 5. Results obtained for disc based actuators when using the whole back area of the plate as a sensor; mode - number of mode; type - full actuator, actuator-sensor; $U_{a}$ - amplitude of the voltage applied to the actuator; $\varphi_{a}$ - phase of the voltage applied to the actuator; $L_{\text {red }}$ - vibration reduction

\begin{tabular}{|c|c|c|c|c|}
\hline Mode & Type & $\begin{array}{l}U_{a} \\
{[\mathrm{~V}]}\end{array}$ & $\begin{array}{l}\varphi_{a} \\
{\left[^{\circ}\right]}\end{array}$ & $\begin{array}{l}L_{\text {red }} \\
{[\mathrm{dB}]}\end{array}$ \\
\hline$\overline{1}$ & \multirow{4}{*}{ actuator } & 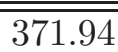 & $\bar{~} 180.00$ & 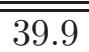 \\
\hline 2 & & 58.71 & 360.00 & 43.3 \\
\hline 4 & & 12.12 & 180.00 & 25.8 \\
\hline 5 & & 161.98 & 360.00 & 35.1 \\
\hline 1 & \multirow{4}{*}{$\begin{array}{c}\text { actuator-sensor } \\
\text { (larger) }\end{array}$} & 499.57 & 180.00 & 39.9 \\
\hline 2 & & 79.02 & 360.00 & 43.3 \\
\hline 4 & & 16.48 & 180.00 & 26.0 \\
\hline 5 & & $\begin{array}{l}219.78 \\
\end{array}$ & 360.00 & 35.5 \\
\hline 1 & \multirow{4}{*}{$\begin{array}{l}\text { actuator-sensor } \\
\text { (smaller) }\end{array}$} & 396.11 & 180.00 & 40.3 \\
\hline 2 & & 62.53 & 360.00 & 43.3 \\
\hline 4 & & 13.00 & 180.00 & 25.9 \\
\hline 5 & & 173.38 & 360.00 & 35.5 \\
\hline
\end{tabular}

Table 5 presents the results of vibration reduction for disc based actuators when using the whole back area of the plate used as a sensor. As mentioned before, this will be treated as a base for the results obtained when using disc based piezoelectric elements. 
Similarly as when using square based elements, there are no significant differences in the vibration reduction levels obtained when using different types of actuators (the largest difference is about $0.5 \mathrm{~dB})$.

And again the trade off of turning off the part of the actuator is the need for higher voltages applied to the said actuator. But, similarly to square based actuators, this can be mitigated by reducing the area that was turned off.

Table 6 presents results of vibration reduction levels using disc based actuators when introducing a virtual sensor placed on the same diagonal as actuators, but in the upper right quarter of the plate. Again, there are no significant differences in the obtained levels of vibration reduction between the 3 piezoelectric actuators (the largest being $0.2 \mathrm{~dB}$ ). And again, the increase in the voltages needed for the said reduction can be mitigated by reducing the size of the sensor part of the sensor-actuator.

Table 6. Results obtained for disc based actuators when using a "virtual" sensor on the diagonal in the upper side of the plate; mode - number of mode; type - full actuator, actuator-sensor; $U_{a}$ - amplitude of the voltage applied to the actuator; $\varphi_{a}$ - phase of the voltage applied to the actuator; $L_{r e d}$ - vibration reduction; $L_{r e d f}$ - vibration reduction calculated for all nodes making the back of the plate

\begin{tabular}{|c|c|c|c|c|c|}
\hline Mode & Type & $\begin{array}{l}U_{a} \\
{[\mathrm{~V}]}\end{array}$ & $\begin{array}{l}\varphi_{a} \\
{\left[^{\circ}\right]}\end{array}$ & $\begin{array}{l}L_{\text {red }} \\
{[\mathrm{dB}]}\end{array}$ & $\begin{array}{l}L_{\text {redf }} \\
{[\mathrm{dB}]}\end{array}$ \\
\hline$\overline{1}$ & \multirow{4}{*}{ actuator } & $\begin{array}{c}371.99 \\
\end{array}$ & $\begin{array}{c}180.00 \\
\end{array}$ & 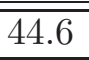 & 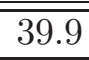 \\
\hline 2 & & 58.75 & 360.00 & 53.3 & 43.1 \\
\hline 4 & & 12.26 & 180.00 & 23.8 & 26.0 \\
\hline 5 & & 162.68 & 360.00 & 31.5 & 35.4 \\
\hline 1 & \multirow{4}{*}{$\begin{array}{l}\text { actuator-sensor } \\
\text { (larger) }\end{array}$} & 499.88 & 180.00 & 44.6 & 40.0 \\
\hline 2 & & 78.94 & 360.00 & 53.5 & 43.2 \\
\hline 4 & & 16.53 & 180.00 & 23.8 & 26.0 \\
\hline 5 & & 220.01 & 360.00 & 31.5 & 35.5 \\
\hline 1 & \multirow{4}{*}{$\begin{array}{l}\text { actuator-sensor } \\
\text { (smaller) }\end{array}$} & 396.14 & 180.00 & 44.6 & 40.3 \\
\hline 2 & & 62.52 & 360.00 & 53.3 & 43.2 \\
\hline 4 & & 13.09 & 180.00 & 23.8 & 25.9 \\
\hline 5 & & 173.62 & 360.00 & 31.5 & 35.4 \\
\hline
\end{tabular}

Table 7 presents results of vibration reduction levels for disc based actuators when using a virtual sensor placed under the centre of the actuator (or sensor-actuator) used for reduction. A similar situation can be observed as for square based actuators. Vibration reduction obtained when using the sensor-actuator with a larger sensor part seems to be slightly higher. But when compared to the recalculated values, they are almost the same. And as was for the square based actuators, reducing the sensor size mitigates this "false" reading.

Figure 3 shows the recalculated values of the reduction of vibration levels using different sensor placements and sizes for the square based actuators. It can be seen that when using a virtual sensor placed under the actuator (the case corresponding to the assumptions of our sensor-actuator), the recalculated reductions of vibration levels are lower for the 1st and 5th mode when compared to the base. For the 1st mode, the difference ranges from $2.1 \mathrm{~dB}$ for the standard actuator and the sensor-actuator with a larger sensor part to $2.4 \mathrm{~dB}$ for the sensor-actuator with a smaller part. And for the 5 th mode, these differences range from $0.4 \mathrm{~dB}$ for the sensor-actuator with a larger sensor part to $0.6 \mathrm{~dB}$ for the standard actuator and the sensor-actuator with a smaller sensor part. Since the difference between the results of two sensor-actuator are small $(0.3 \mathrm{~dB}$ for the 1 st mode and $-0.2 \mathrm{~dB}$ for the 5 th mode) it is at this stage 
Table 7. Results obtained for disc based actuators when using a "virtual" sensor placed under the centre of the disc based actuator; mode - number of mode; type - full actuator, actuator-sensor; $U_{a}$ - amplitude of the voltage applied to the actuator; $\varphi_{a}$-phase of the voltage applied to the actuator; $L_{r e d}$ - vibration reduction; $L_{r e d f}$ - vibration reduction calculated for all nodes making the back of the plate

\begin{tabular}{|c|c|c|c|c|c|}
\hline Mode & Type & $\begin{array}{l}U_{a} \\
{[\mathrm{~V}]}\end{array}$ & $\begin{array}{l}\varphi_{a} \\
{\left[^{\circ}\right]}\end{array}$ & $\begin{array}{l}L_{\text {red }} \\
{[\mathrm{dB}]}\end{array}$ & $\begin{array}{l}L_{\text {redf }} \\
{[\mathrm{dB}]}\end{array}$ \\
\hline 1 & \multirow{4}{*}{ actuator } & 370.41 & 180.00 & 25.2 & 38.6 \\
\hline 2 & & 58.67 & 360.00 & 41.6 & 43.2 \\
\hline 4 & & 12.24 & 180.00 & 31.8 & 26.0 \\
\hline 5 & & 162.36 & 360.00 & 33.0 & 34.9 \\
\hline 1 & \multirow{4}{*}{$\begin{array}{l}\text { actuator-sensor } \\
\text { (larger) }\end{array}$} & 497.95 & 180.00 & 25.7 & 38.8 \\
\hline 2 & & 79.01 & 360.00 & 42.3 & 43.3 \\
\hline 4 & & 16.51 & 180.00 & 32.0 & 26.0 \\
\hline 5 & & 219.60 & 360.00 & 34.2 & 35.4 \\
\hline 1 & \multirow{4}{*}{$\begin{array}{l}\text { actuator-sensor } \\
\text { (smaller) }\end{array}$} & 394.41 & 180.00 & 25.2 & 38.8 \\
\hline 2 & & 62.53 & 360.00 & 41.6 & 43.3 \\
\hline 4 & & 13.02 & 180.00 & 31.7 & 25.9 \\
\hline 5 & & 173.23 & 360.00 & 33.1 & 35.4 \\
\hline
\end{tabular}

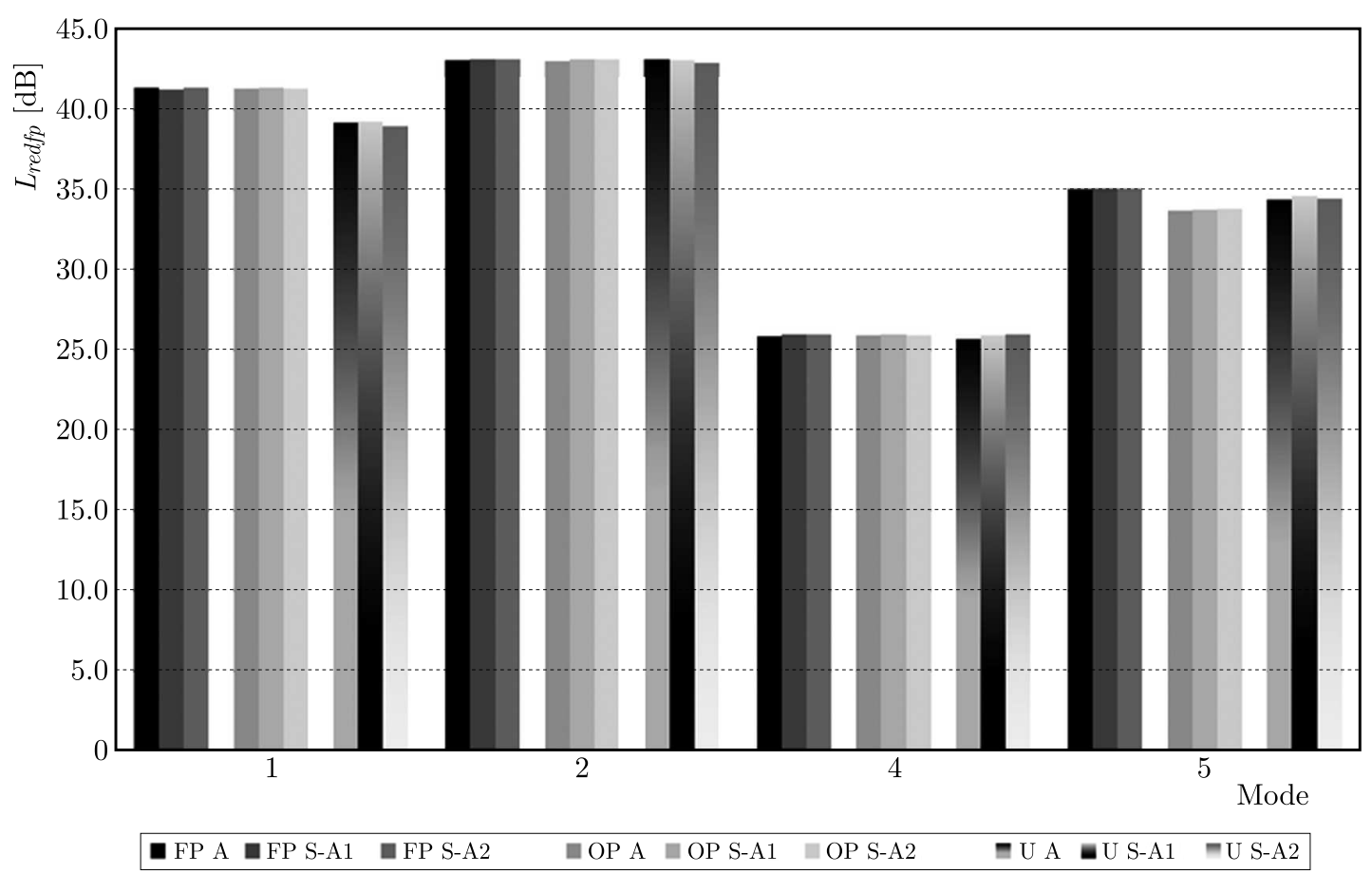

Fig. 3. Comparison of the vibration reduction level for square based actuators when recalculated to the $L_{\text {redf }}$; the FP stands for when using the whole plate as a sensor; OP when using the sensor placed on the diagonal in the upper part of the plate; $\mathrm{U}$ when using the sensor placed under the actuator; $\mathrm{A}$ is

the "standard" actuator, S-A-1 is the sensor-actuator with a larger sensor part, S-A-2 is the sensor-actuator with a smaller sensor part

impossible to determine whether these are a result of reducing the sensor part, or "imperfections" in the model or optimization algorithm.

Figure 4 shows the recalculated values of the reduction of vibration levels using different sensor placements and sizes for the disc based actuators. It can be seen for disc shaped actuators 


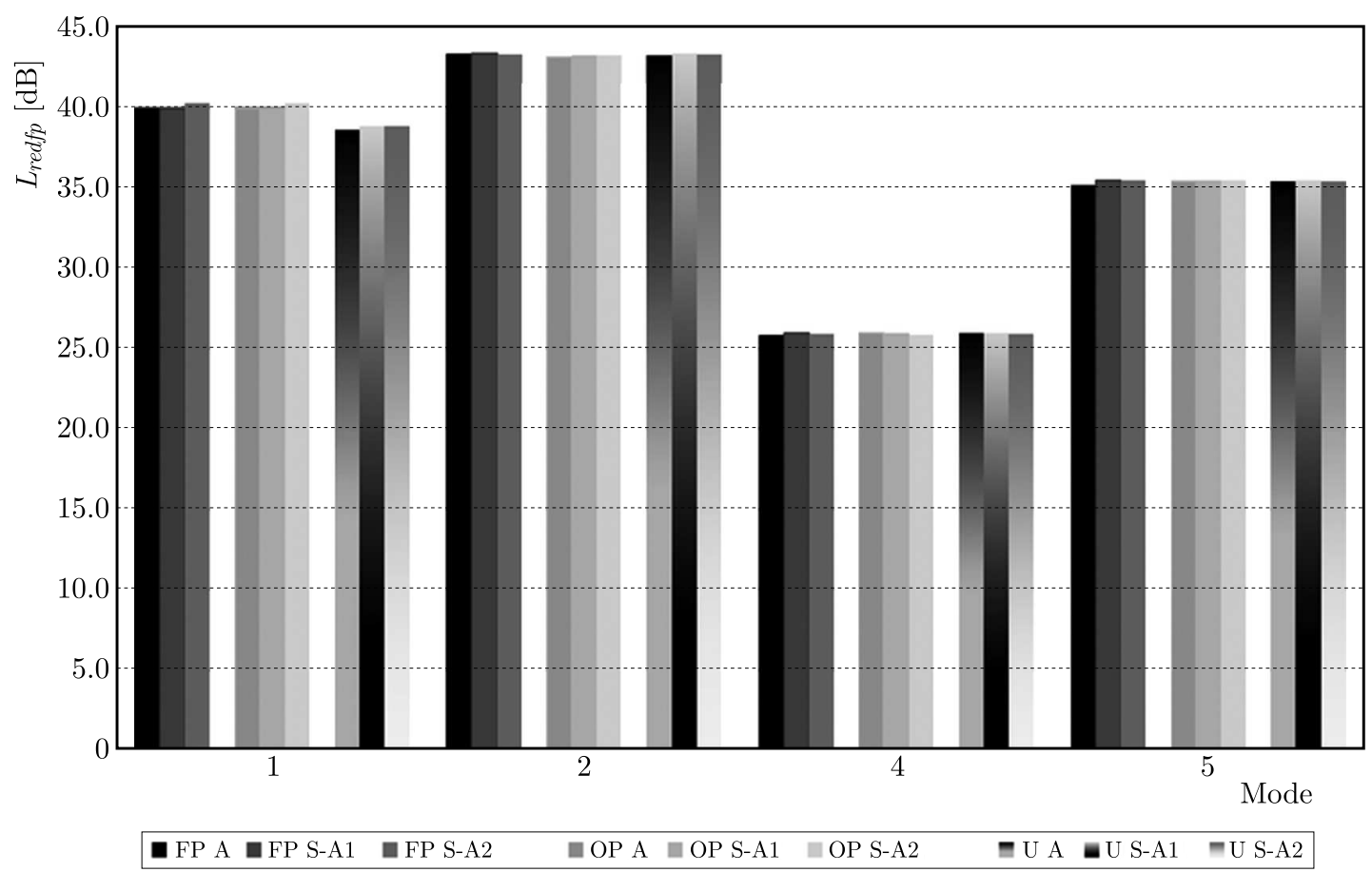

Fig. 4. Comparison of the vibration reduction level for disc based actuators when recalculated to the $L_{\text {redf }}$; the FP stands for when using the whole plate as a sensor; OP when using the sensor placed on the diagonal in the upper part of the plate; $\mathrm{U}$ when using the sensor placed under the actuator; $\mathrm{A}$ is

the "standard" actuator, S-A-1 is the sensor-actuator with a larger sensor part, S-A-2 is the sensor-actuator with a smaller sensor part

that the differences in the obtained vibration levels reduction when using different sizes and placements of the sensor are present only for the 1st mode, and are only present when using the sensor placed directly under the actuator. These differences are also smaller than for the square based actuators, with the largest being $1.5 \mathrm{~dB}$.

It can be assumed that using the sensor-actuator can, in some situations, limit the level of vibration reduction that could be obtained with the actuator because of the sensor placement. Of course, it should be noted that the placement of actuators for the models was chosen so as to be able to deal with all the modes analyzed. Perhaps, a change in placement of the actuator could somewhat mitigate these lower levels of vibration reduction.

Also it appears that reducing the sensor part of the sensor actuator does not have a significant impact on its function as a sensor, at least in the extent showed in this paper. Of course, there should be a moment where reducing the size of the sensor part will start to impact the results, and the actual size will be determined by physical limitations of the sensor and possible manufacturing difficulties.

\section{Conclusions}

This paper presented results of preliminary simulations of a piezoelectric sensor-actuator hybrid. There were four questions to be answered. First, how would the said hybrid behave when compared to a standard, homogenous piezoelectric actuator in terms of obtainable vibration reduction. The second question was would the sensor part be useful. The third question was how would the change in size of the sensor part of the said actuator impact the actuator part of this hybrid. And finally how would reducing the size of the sensor work out.

As for the differences between the standard actuator and the sensor-actuator in terms of vibration reduction, there were no significant differences in the obtained levels of vibration 
reduction between the standard actuator and the sensor-actuator regardless of the sensor part size. There were differences in the amplitudes of the voltage needed to be applied to the actuator to obtain the said reduction. Reducing the size of the sensor part allowed one to lower the voltage amplitudes needed to obtain the said reduction.

When using a sensor placed directly under the actuator and with the size corresponding to the sensor part of the sensor actuator (a situation corresponding to using the sensor part of the sensor-actuator) it can be observed that for some of the modes, a lower reduction was obtained (when compared to the base). This appears to be influenced by the shape of the actuator but not by the size of the sensor part (at least in the range of the presented results). This allows for an assumption that the actual limitations on the size of the sensor part will come from the physical limitations of the sensor size and/or manufacturing difficulties.

\section{Acknowledgements}

The work described in this paper has been executed within statutory activities of the Faculty of Mechanical Engineering and Robotics of AGH - University of Science and Technology No. 16.16.130.942.

\section{References}

1. Augustyn E., Kozień M.S., 2015, A study on possibility to apply piezoelectric actuators for active reduction of torsional beams vibrations, Acta Physica Polonica A, 125, 4A, A-164-A-168, DOI: 10.12693/APhysPolA.125.A-164

2. Fuller C.R., Jones J.D., 1987, Experiments on reduction of propeller induced interior noise by active control of cylinder vibration, Journal of Sound and Vibration, 112, 389-395, DOI: 10.1016/S0022-460X(87)80208-0

3. Fuller C.R., Elliott S.J., Nelson P.A., 1996, Active Control of Vibration, Academic Press, London

4. Gardonio P., 2006, Sensor-actuator transducers for smart panels, Proceedings of the ACTIVE, Sydney

5. Gardonio P., Elliott S.J., 2005, Smart panels with velocity feedback control systems using triangularly shaped strain actuators, Journal of the Acoustical Society of America, 117, 2046, DOI: $10.1121 / 1.1863092$

6. Hansen C.H., Snyder S.D., 1997, Active Control of Noise and Vibration, E\&FN Spon, London

7. Kundu A., BerRy A., 2011, Active control of transmission loss with smart foams, Journal of the Acoustical Society of America, 129, 726, DOI: 10.1121/1.3519676

8. Loy C.T., Lam K.Y., Reddy J.N., 1999, Vibration of functionally graded cylindrical shells, International Journal of Mechanical Sciences, 41, 309-324, DOI: 10.1016/S0020-7403(98)00054-X

9. Pietrzakowski M., 2007, Vibration control of functionally graded piezoelectric plates, Mechanics, 26, 4, 181-186

10. Szemela K., Rdzanek W.P., ŻyŁKa W., 2018, The radiation efficiency measurements of real system of a thin circular plate embedded into a thick square baffle, Archives of Acoustics, 43, 3, 413-423, DOI: $10.24425 / 123913$

11. Trojanowski R., Wiciak J., 2012, Comparison of efficiency of different shapes of homogeneous and two-part piezo elements on vibration reduction, Acta Physica Polonica A, 122, 5, 905-907, DOI: 10.12693/APhysPolA.122.905

12. Tylikowski A., 2001, Simulation study of actuators made of piezo electric gradient materials (in Polish), Proceedings of the VIII Warsztaty Naukowe Polskiego Towarzystwa Symulacji Komputerowej "Symulacja w badaniach i rozwoju", T. Krzyżyński, A. Tylikowski (Edit.), 384-388 
13. Tylikowski A., 2004, The influence of electrical and electromechanical properties of functionally graded piezoelectric actuators, Proceedings of the XI Warsztaty Naukowe Polskiego Towarzystwa Symulacji Komputerowej w badaniach i rozwoju”, T. Krzyżyński, A. Tylikowski (Edit.), 14-21

14. Wiciak M., Trojanowski R., 2014, Numerical analysis of the effectiveness of two-part piezoactuators in vibration reduction of plates, Acta Physica Polonica A, 125, 4A, A-183-A-189, DOI: 10.12693/APhysPolA.125.A-183

15. Wiciak J., Trojanowski R., 2015a, Comparison of vibration and acoustic pressure reduction using different types of piezo actuators, Acta Physica Polonica A, 128, 1A, A-62-A-66, DOI: 10.12693/APhysPolA.128.A-62

16. Wiciak J., Trojanowski R., 2015b, Evaluation of the effect of a step change in piezo actuator structure on vibration reduction level in plates, Archives of Acoustics, 40, 1, 71-79, DOI: 10.1515/aoa-2015-0009

17. ŻoŁopa E., Brański A., 2014, Analytical determination of optimal actuators position for single mode active reduction of fixed-free beam vibration using the linear quadratic problem idea, Acta Physica Polonica A, 125, 4, A-155-A-158, DOI: 10.12693/aphyspola.125.a-155 